\title{
Yetişkinlerde Konserve Balık Tüketimine Bağlı Ağır Metal Maruziyet Riskinin Değerlendirilmesi
}

\author{
Evaluation of the Heavy Metal Exposure Risk Due to Canned Fish Consumption in Adults
}

\author{
Seray Akalın¹, Elif İnan Eroğlu², Atila Güleç3, Aylin Ayaz ${ }^{4}$
}

Geliş tarihi/Received: $18.02 .2020 \bullet$ Kabul tarihi/Accepted: 14.07 .2020

\section{ÖZET}

Amaç: Bu çalışma, Ankara piyasasında satılan 7 farklı türe ait (ton, sardalya, somon, uskumru, hamsi, alabalık ve levrek) 66 adet konserve balığın ağır metal içeriklerini analiz etmek ve yetişkin bireylerin ağır metal maruziyet düzeylerinin saptanarak risk değerlendirmesini yapmak amacıyla planlanmış ve yürütülmüştür.

Gereç ve Yöntem: Tüm konserve balık örneklerinin ICP-MS (indüktif eşleşmiş plazma-kütle spektrometresi) cihazında kurşun $(\mathrm{Pb})$, kadmiyum (Cd), alüminyum (Al) ve arsenik (As) analizleri yapılmıştır. Yetişkin bireylerin haftada 2 porsiyon konserve balık tüketmeleri halinde maruz kalacakları $\mathrm{Pb}, \mathrm{Cd}$, Al ve As düzeyleri hesaplanmıştır.

Bulgular: Analiz edilen balıklar içerisinde $\mathrm{Pb}$ ve $\mathrm{Cd}$ açısından en yüksek içeriğe sahip olan tür ton balığıdır (sırasıyla; $0.12 \pm 0.16 \mathrm{mg} / \mathrm{kg}, 6.41 \pm 4.98 \mathrm{mcg} / \mathrm{kg})$. Alüminyum açısından en yüksek konsantrasyona sahip konserve hamsi iken $(1.91 \pm 0.15$ $\mathrm{mg} / \mathrm{kg})$, As açısından en yüksek düzey sardalya da $(2.16 \pm 1.13 \mathrm{mg} / \mathrm{kg})$ belirlenmiştir. Araştırma sonuçlarına göre yetişkin bireylerde $\mathrm{Pb}, \mathrm{Cd}$, Al ve As maruziyetinin Besin ve İlaç İdaresi (FDA) ve Gıda Katkı Maddeleri Ortak FAO/WHO Uzmanlar Komitesi (JECFA) tarafından belirlenen üst limitlerin altında olduğu saptanmıştır.

Sonuç ve Öneriler: Günümüzde konserve balıklar ulaşılabilirlik ve tüketim kolaylığı nedeniyle tercih edilmektedir. Ancak taze veya konserve balıklar diyetimizde ağır metaller yönünden de potansiyel bir risk olarak gösterilmektedir. Bu çalışmada, piyasada satılan farklı içeriğe sahip konserve balıkların farklı düzeylerde ağır metal içeriğine sahip olduğu ve yetişkinlerin farklı düzeylerde ağır metale maruz kaldığı saptanmıştır. Piyasada satışa sunulan farklı türde konserve balıkların günlük tüketim miktarlarına göre farklı yaş gruplarındaki bireylerin ağır metal maruziyet riskini değerlendiren çalışma sayısı oldukça azdır. Bu konuda daha kapsamlı çalışmaların yapılması gerekmektedir.

Anahtar kelimeler: Konserve balık, ağtr metaller, maruziyet düzeyi, risk, yetişkinler

\begin{abstract} risk assessment.

1. İletişim/Correspondence: Hacettepe Üniversitesi, Sağllk Bilimleri Fakültesi, Beslenme ve Diyetetik Bölümü, Ankara, Türkiye

E-posta: serayakalinn@gmail.com • — https://orcid.org/0000-0002-8802-8918

2. Hacettepe Üniversitesi, Sağlık Bilimleri Fakültesi, Beslenme ve Diyetetik Bölümü, Ankara, Türkiye • • ํ https://orcid.org/0000-0001-9788-7266
\end{abstract}

Objective: The aim of this study was to analyze the metals lead ( $\mathrm{Pb})$, cadmium (Cd), aluminium (Al) and arsenic (As) in 66 canned fish from 7 different species (ton, sardine, salmon, mackerel, anchovies, trout and perch) sold in Ankara supermarkets and to determine the heavy metal exposure levels of adult individuals depending on consumption of canned fish and make
3. Hacettepe Üniversitesi, Sağllk Bilimleri Fakültesi, Beslenme ve Diyetetik Bölümü, Ankara, Türkiye • • $\odot$ https://orcid.org/0000-0003-2569-2317

4. Hacettepe Üniversitesi, Sağlık Bilimleri Fakültesi, Beslenme ve Diyetetik Bölümü, Ankara, Türkiye • $\odot$ https://orcid.org/0000-0002-3543-7881 
Materials and Methods: Levels of lead ( $\mathrm{Pb})$, cadmium (Cd), aluminum (Al) and arsenic (As) of samples were determined using ICP-MS (inductively coupled plasma-mass spectrometry). And the exposure of selected heavy metal levels was calculated that adults would be exposed to if they consume two portions of canned fish per week.

Results: The canned tuna which has the highest content in terms of $\mathrm{Pb}$ and $\mathrm{Cd}$ among the analyzed fish $(0.12 \pm 0.16 \mathrm{mg} / \mathrm{kg}$, $6.41 \pm 4.98 \mathrm{mcg} / \mathrm{kg}$, respectively). While the highest concentration canned anchovy $(1.91 \pm 0.15 \mathrm{mg} / \mathrm{kg})$ in terms of Al, the highest concentration of As was also determined in canned sardines $(2.16 \pm 1.13 \mathrm{mg} / \mathrm{kg})$. According to the findings, it was determined that the exposure of $\mathrm{Pb}, \mathrm{Cd}, \mathrm{Al}$ and $\mathrm{As}$ in adult individuals was below the upper limits set by Food and Drug Administration (FDA) and Joint FAO/WHO Expert Committee on Food Additives (JECFA).

Conclusion: At the present time, canned fish are preferred due to their accessibility and ease of consumption. However, fresh or canned fish are also shown as a potential risk for heavy metals in our diet. In this study, it has been determined that canned fish with different content sold in the market have different levels of heavy metal content and adults are exposed to different levels of heavy metal. The number of studies assessing the heavy metal exposure risk of individuals for different age groups according to the amount of daily consumption of different types of canned fish is very scarce. Further studies are required.

Keywords: Canned fish, heavy metals, exposure level, risk, adults

\section{GíRIŞ}

Ağır metaller, atomik yoğunluğu sudan 5 kat veya daha yüksek oranda olan metal ve metalloidleri kapsayan elementler olarak tanımlanmaktadır. $\mathrm{Bu}$ metallerin düşük konsantrasyonlarının toksik etki gösterebileceği bildirilmiştir (1). Hızlı kentleşme ve gelişen endüstriyel uygulamalara bağlı olarak metallerin kullanımı ve çevreye salınımları artış göstermektedir. Ağır metaller yaygın kullanımları nedeniyle önemli çevresel kirleticilerdendir (2).

Günümüzde ağır metaller farklı alanlarda kullanılmaktadır. Insanlar çeşitli kaynaklar aracılığı ile ağır metallere maruz kalmaktadır. Bunlar; beslenme, hava, toprak ve mesleki maruziyettir. Besinler üretimtüketim zincirinin çeşitli aşamalarında bu çevresel kirleticilere maruz kalabilirler. Besinlerde bulunan ağır metaller de besine istemsizce bulaşan kimyasal kontaminantlardan biridir (2). Son ylllarda sular ve buna bağlı olarak suda yaşayan canlılar ağır metal içeriği yönünden ilgi çekmektedir (3).

Canlıların ağır metallere maruziyeti konusunda üzerinde en çok araştırma yapılan ve tartışılan metallerden bazıları kurşun, kadmiyum, alüminyum ve arseniktir. Kurşun (Pb), insanlar tarafindan birçok alanda kullanılan bir ağır metaldir $(4,5)$. Son üç yüzyılda (özellikle 1950-2000 yllları arasında) çevreye salınan kurşun miktarının 1000 kat arttı̆̆ı bildirilmiştir (6). Kurşun maruziyetinde temel kaynaklar; su, besinler, toprak, mutfak eşyaları, bataryalar, kablolar, kurşunlu boyalar, insektisitler, sırlama malzemeleri ve kurşunlu benzindir $(5,7)$. Kurşun maruziyeti, özellikle gelişmekte olan ülkelerde önemli bir toplum sağlığı sorunudur (4).

Kadmiyum (Cd), ilk olarak 1. Dünya Savaşı döneminde kullanılmaya başlanarak günümüzde şarj edilebilir pillerde, çeşitli alaşımlarda ve tütünde kullanılmaktadır (8). Kadmiyum maruziyetinde ise temel olarak iki yol bulunmaktadır. Birincisi, su ve besin (özellikle yeşil yapraklı sebzeler, patates, tahıllar, yer fıstığı, soya fasulyesi ve balık), ikincisi ise solunum yoluyla olmaktadır. Besin ve sudaki kadmiyumun \%1-10’u sindirim kanalıyla vücuda alınmaktadır (9).

Yer kabuğunda üçüncü en çok bulunan element olan Alüminyum (Al) hafif ağırlığı, esnekliği, işlenebilirliği, iyi termal ve elektrik iletkenliği, yüksek yansıtma özelliği ve üstün bariyer kalitesi nedeniyle transport, ev eşyaları, paketleme materyali ve ilaçlar başta olmak üzere sanayide yaygın bir şekilde kullanılmaktadır. 
Aynı zamanda nem önleyici, sertleştirici, beyazlatıcı, topaklanmayı önleyici özellikleri nedeniyle besinlerde gıda katkı maddesi olarak da kullanılmaktadır (10). İnsan vücuduna alınan $\mathrm{Al}$ metalinin büyük kısmının besinlerle olduğu düşünülmektedir (11). Besinin alüminyum içeriği depolanma ve işlenme koşullarına göre de farklılık gösterebilmektedir. Alüminyumun birçok alanda kullanılmasına bağlı olarak bireylerin maruziyet düzeyleri artacağından bu konudaki risk faktörleri iyi değerlendirilmelidir (10).

Arsenik (As), doğada oluşabilen, toprak, su, hava ve yiyeceklerde bulunabilen bir kirleticidir (12). Arsenik endüstriyel ürünler, cam üretimi, bakırkurşun dökümü, jeotermal atıkları yoluyla çevreye yayıldığı gibi çeşitli fungusitler ve pestisitler yoluyla da kontaminasyona neden olmaktadır (13). Arsenik maruziyetinde özellikle içme suları, balık ve deniz ürünleri başlıca kaynaklardır (14). Besinler ile maruz kalınan arsenik miktarı, balık ve deniz ürünleri tüketimine bağlı olarak bölgeden bölgeye değişiklik gösterebilmektedir (13).

Ağır metallere maruziyetin değerlendirilmesinde çeşitli etmenler rol oynamaktadır. Yaş, cinsiyet, sosyoekonomik düzey, beslenme durumu, genetik özellikler bu etmenlerden bazılarıdır (15).

Ülkemizde yapılan Türkiye Beslenme ve Sağlık Araştırmasının sonuçlarına göre 20 yaş üstü yetişkin bireylerin \%17.2'sinin haftada 1-2 kez, \%14.8'inin 15 günde 1 kez, \%25.2'sinin ise ayda 1 kez balık tükettiği, \%39.1'inin ise balık tüketmediği belirtilmektedir (16). $\mathrm{Bu}$ çalışmanın amacı yetişkin bireylerde konserve balık tüketimine bağlı olarak $\mathrm{Pb}, \mathrm{Cd}$, Al ve As maruziyet düzeylerinin belirlenerek risk değerlendirilmesinin yapılmasıdır.

\section{GEREÇ VE YÖNTEM}

\section{Örneklerin Hazırlanması ve Ağır Metal Analizi}

$\mathrm{Bu}$ çalışmada, Ankara piyasasında satılan farklı içeriğe sahip 66 adet konserve balık kendi orijinal ambalajında satın alınarak araştırmacılar tarafından Hacettepe Üniversitesi Beslenme ve Diyetetik Bölümü
Orhan Köksal Araştırma Laboratuvarında analiz edilmiştir. Numuneler içeriklerindeki balık türlerine göre farklı sınıflara ayrılmıştır. Numuneler satın alındıktan sonra kendi ambalajlarında analiz edilene kadar saklanmıştır. Her bir numunede ağır metallerin ( $\mathrm{Pb}, \mathrm{Cd}, \mathrm{Al}$ ve $\mathrm{As})$ analizleri yapılmıştır.

Numunelerin ağır metal analizinde kullanılan tüm kimyasallar ve çözeltiler analitik düzey kalitesindedir. Nitrik asit $\left(\mathrm{HNO}_{3}-\geq \% 65\right)$ (Merck-Germany), indüktif eşleşmiş plazma-kütle spektrometresi (ICP-MS) Tuning çözeltisi; Tune D (High-Purity StandardsCharleston-USA), $\mathrm{Pb} / \mathrm{Cd} / \mathrm{Al} / \mathrm{As}$ için tekli element standartları (1000 mcg/mL in \%2 $\mathrm{HNO}_{3}$ ) (High-Purity Standards-Charleston-USA), ultra saf su, yüksek saflıkta (\%99.998) argon gazı kullanılmıştır. İndüktif eşleşmiş plazma-kütle spektrometresi cihazında ağır metal tayini öncesi numunelerin organik bileşenleri mikrodalgada (CEM-Mars) nitrik asitle 50 mL'lik teflon XP-1500 Plus hücrelerde yakılmıştır. Daha sonra ağır metal analizi için Thermo Electron marka, X series II model ICP-MS cihazı kullanılmıştır. Analiz edilen tüm konserve balık örneklerinin ağır metal miktarları yaş ağırlık (YA) üzerinden değerlendirilmiştir $(17,18)$.

\section{Ağır Metal Maruziyetinin Değerlendirilmesi}

Numunelerin ağır metal içerikleri analiz edildikten sonra yetişkin bireylerde konserve balık tüketimine bağlı olarak $\mathrm{Pb}, \mathrm{Cd}$, Al ve As maruziyeti hesaplanmıştır. Analiz edilen ağır metallerin çeşitli kuruluşlarca belirlenen maksimum maruziyet düzeyleri göz önünde bulundurularak risk değerlendirmesi yapılmıştır. Gıda Katkı Maddeleri Ortak FAO/WHO Uzmanlar Komitesi (JECFA)'ne göre bireylerin tolere edebilecekleri maksimum düzeyler; kadmiyum için $25 \mathrm{mcg} / \mathrm{kg}$ vücut ağırlığı (VA)/ay (19), alüminyum için $2 \mathrm{mg} / \mathrm{kg}$ vücut ağırlığı/hafta'dır (20). Gıda Katkı Maddeleri Ortak FAO/WHO Uzmanlar Komitesine göre diyetle kurşun alımı için tolere edilebilen maksimum düzey bildirilmemiştir ancak Besin ve İlaç Dairesi'ne (FDA) göre bireylerin günlük maruz kalabileceği $\mathrm{Pb}$ seviyesi en fazla $0.006 \mathrm{mg} / \mathrm{kg} \mathrm{VA} /$ gün olarak belirlenmiştir (21). Gıda Katkı Maddeleri Ortak FAO/WHO Uzmanlar Komitesine göre tolere 
edilebilen düzey inorganik arsenik bileşikleri için $0.015 \mathrm{mg} / \mathrm{kg} \mathrm{VA} / \mathrm{hafta}$, organik arsenik bileşikleri için $0.05 \mathrm{mg} / \mathrm{kg}$ VA/hafta'dır (22). Fakat günümüzde JECFA ve Amerika Birleşik Devletleri Çevre Koruma Ajansı (EPA-Environmental Protection Agency) bu üst limitin koruyucu etkisinin olmadığını belirtmektedir (20). Arseniğin tolere edilebilen üst limitini belirleme konusunda araştırmalar devam etmektedir. Bireylerin ağır metal maruziyetlerinin değerlendirilmesinde $\mathrm{Pb}$ için FDA'nın belirlediği üst limit, $\mathrm{Cd}$, $\mathrm{Al}$ ve As için ise JECFA'nın belirlediği üst limit esas alınmıştır (19-21).

Maruziyetin değerlendirilmesinde kullanılacak vücut ağırlığı için Türkiye Beslenme ve Sağlık Araştırması (TBSA) 2010 verileri kullanılmıştır. Yetişkin erkeklerin (19 yaş ve üstü) ortalama vücut ağırlığı $77.9 \mathrm{~kg}$, yetişkin kadınların (19 yaş ve üstü) ise $71.1 \mathrm{~kg}$ olarak alınmıştır (16). Bireylerin ağır metallere maruziyet düzeyleri, Türkiye Beslenme Rehberinde (2015) (TÜBER) et ve et ürünlerinin günlük tüketimine yönelik önerilen miktarlar dikkate alınarak değerlendirilmiştir (23). Yetişkin bireylerin haftada 2 porsiyon konserve balık (balık için porsiyon gramajı: $150 \mathrm{~g}$ ) tükettikleri düşünülerek hesaplamalar yapılmıştır (23).

\section{Verilerin İstatistiksel Değerlendirmesi}

Verilerin istatistiksel olarak değerlendirilmesinde; IBM SPSS Statistics 22.0 (SPSS Inc., Chicago, USA) programından yararlanılmıştır. Veriler için tanımlayıcı istatistik olarak aritmetik ortalama, standart sapma ve ortanca ile 1. ve 3. kartil (Q1-Q3) değerleri kullanılmıştır (24).

\section{BULGULAR}

Bu çalışmada kullanılan 66 adet farklı balık türlerine ait konservelerin ağır metal düzeyleri Tablo 1'de özetlenmiştir. Analiz edilen balıklar içerisinde $\mathrm{Pb}$ ve Cd açısından en yüksek içeriğe sahip olan tür ton balığıdır (sırasıyla; 0.12 $\pm 0.16 \mathrm{mg} / \mathrm{kg}$ YA, $6.41 \pm 4.98 \mathrm{mcg} /$ $\mathrm{kg}$ YA).
Bireylerin günlük bir porsiyon balık tüketimlerine göre ağır metal maruziyetleri Tablo 2 ve Tablo 3’te verilmiştir. En yüksek $\mathrm{Pb}$ maruziyet düzeyinin ton balığ tüketimiyle olduğu belirlenmiştir (erkeklerde 0.00006 $\pm 0.00009 \mathrm{mg} / \mathrm{kg} \quad$ VA/gün, kadınlarda $0.00007 \pm 0.00010 \mathrm{mg} / \mathrm{kg}$ VA/gün) (Tablo 2) (Şekil 1). Bu araştırma sonuçlarına göre kurşun için en yüksek maruziyet düzeyinin, FDA tarafından belirlenen üst limitin (0.006 mg/kg VA/gün) altında olduğu saptanmıştır.

Kadmiyum için saptanan maruziyet düzeyleri Tablo 2 ve Şekil 2'de gösterilmiştir. Şekil 2'ye göre kurşuna benzer şekilde kadmiyuma en yüksek maruziyet ton balığı konservelerinde saptanmıştır. Bu sonuçlara göre konserve balık tüketimine bağlı Cd maruziyetinin JECFA’nın $25 \mathrm{mcg} / \mathrm{kg}$ VA/ay olarak belirlemiş olduğu üst limitin altında olduğu belirlenmiştir.

Analiz sonuçlarına göre Al içeriği en yüksek olan numune hamsi konserveleridir $(1.91 \pm 0.15 \mathrm{mg} / \mathrm{kg}$ YA) (Tablo 1). Konserve balıkların içerdikleri $\mathrm{Al}$ miktarlarına göre yetişkin kadın ve erkeklerdeki maruziyet düzeyleri Tablo 3 ve Şekil 3’te gösterilmiştir. Buna göre en yüksek Al içeriğine sahip hamsi konservelerinin $(1.91 \pm 0.15 \mathrm{mg} / \mathrm{kg}$ YA) haftada 2 porsiyon tüketimi (300 g) sonucu $\mathrm{Al}$ maruziyet düzeyi JECFA tarafindan belirtilen düzeyin (2 mg/kg VA/hafta) altında bulunmuştur.

$\mathrm{Bu}$ çalışmada As içeriği en yüksek sardalyada $(2.16 \pm 1.13 \mathrm{mg} / \mathrm{kg}$ YA) saptanmıştır (Tablo 1). Buna bağlı olarak en yüksek maruziyet düzeyinin sardalya tüketimi ile olduğu belirlenmiştir (Tablo 3) (Şekil 4). Arsenik için JECFA tarafından belirlenen üst limit (0.015 mg/kg VA/hafta) 2011 yılında koruyucu etkisi olmadığı gerekçesiyle geri çekilmiştir. Haftada 2 porsiyon konserve sardalya tüketimiyle maruz kalınan As miktarı bu belirlenen üst limitin altında bulunmuştur. 
Tablo 1. Farklı balık türüne sahip konserve balıkların ağır metal düzeylerinin ortalama, standart sapma ve ortanca değerleri

\begin{tabular}{|c|c|c|c|c|c|c|c|c|}
\hline \multirow{2}{*}{$\begin{array}{l}\text { Balık Türü } \\
\text { (n) }\end{array}$} & \multicolumn{2}{|c|}{$\mathrm{Pb}$ (mg/kg YA) } & \multicolumn{2}{|c|}{$\mathrm{Cd}$ (mcg/kg YA) } & \multicolumn{2}{|c|}{$\mathrm{Al}$ (mg/kg YA) } & \multicolumn{2}{|c|}{ As (mg/kg YA) } \\
\hline & $\overline{\mathrm{X}} \pm \mathrm{SS}$ & $\begin{array}{l}\text { Ortanca } \\
\text { (Q1-Q3) }\end{array}$ & $\overline{\mathbf{X}} \pm \mathrm{SS}$ & $\begin{array}{l}\text { Ortanca } \\
\text { (Q1-Q3) }\end{array}$ & $\overline{\mathbf{X}} \pm \mathrm{SS}$ & $\begin{array}{l}\text { Ortanca } \\
\text { (Q1-Q3) }\end{array}$ & $\overline{\mathrm{X}} \pm \mathrm{SS}$ & $\begin{array}{l}\text { Ortanca } \\
\text { (Q1-Q3) }\end{array}$ \\
\hline Ton (42) & $0.12 \pm 0.16$ & $0.05(0.02-0.15)$ & $6.41 \pm 4.98$ & $4.98(3.98-9.74)$ & $1.22 \pm 0.82$ & $0.93(0.66-1.52)$ & $0.33 \pm 0.18$ & $0.32(0.22-0.41)$ \\
\hline Alabalık (2) & $0.03 \pm 0.01$ & $0.03(0.02-0.03)$ & $3.35 \pm 2.84$ & $2.54(0.86-6.63)$ & $1.53 \pm 0.48$ & $1.80(1.00-1.81)$ & $0.17 \pm 0.10$ & $0.12(0.11-0.29)$ \\
\hline Hamsi (2) & $0.04 \pm 0.01$ & $0.04(0.03-0.05)$ & $3.79 \pm 1.54$ & $3.59(2.26-5.30)$ & $1.91 \pm 0.15$ & $1.91(1.77-2.06)$ & $0.66 \pm 0.02$ & $0.67(0.64-0.68)$ \\
\hline Sardalya (5) & $0.04 \pm 0.01$ & $0.04(0.03-0.04)$ & $1.12 \pm 4.25$ & $1.99\left(\mathrm{ND}^{*}-3.9\right)$ & $1.19 \pm 0.71$ & $0.98(0.59-1.75)$ & $2.16 \pm 1.13$ & $2.25(0.91-3.22)$ \\
\hline Somon (6) & $0.08 \pm 0.08$ & $0.05(0.02-0.14)$ & $0.19 \pm 1.51$ & $0.19\left(\mathrm{ND}^{*}-1.57\right)$ & $1.27 \pm 0.44$ & $1.34(0.77-1.74)$ & $0.23 \pm 0.17$ & $0.18(0.06-0.33)$ \\
\hline Uskumru (8) & $0.08 \pm 0.10$ & $0.03(0.02-0.10)$ & $5.03 \pm 2.74$ & $4.89(3.16-7.64)$ & $1.77 \pm 1.35$ & $1.45(0.63-2.61)$ & $0.66 \pm 0.15$ & $0.63(0.52-0.84)$ \\
\hline Levrek (1) & $0.03 \pm 0.01$ & $0.03(0.02-0.03)$ & $0.32 \pm 0.07$ & $0.3(0.28-0.35)$ & $1.05 \pm 0.11$ & $1.06(0.94-1.15)$ & $0.09 \pm 0.003$ & $0.09(0.09-0.09)$ \\
\hline Toplam (66) & $0.10 \pm 0.14$ & $0.04(0.02-0.12)$ & $5.00 \pm 4.09$ & $4.48(2.44-7.43)$ & $1.32 \pm 0.87$ & $1.01(0.69-1.76)$ & $0.50 \pm 0.61$ & $0.34(0.21-0.50)$ \\
\hline
\end{tabular}
*ND: Tespit edilememiştir.

Tablo 2. Yetişkin bireylerin konserve balık tüketimlerine bağlı $\mathrm{Pb}$ ve $\mathrm{Cd}$ maruziyet düzeyleri $\overline{\mathrm{X}} \pm \mathrm{SS}$

\begin{tabular}{lcccc}
\hline \multirow{2}{*}{$\begin{array}{l}\text { Balık Türü } \\
\text { (n) }\end{array}$} & \multicolumn{2}{c}{ Pb (mg/kg VA/gün) } & \multicolumn{2}{c}{ Cd (mcg/kg VA/ay) } \\
\cline { 2 - 5 } Ton (42) & Erkek & Kadın & Erkek & Kadın \\
Alabalık (2) & $0.00006 \pm 0.00009$ & $0.00007 \pm 0.00010$ & $0.00011 \pm 0.00006$ & $0.00011 \pm 0.00006$ \\
Hamsi (2) & $0.00002 \pm 0.00001$ & $0.00001 \pm 0.00000$ & $0.00006 \pm 0.00005$ & $0.00006 \pm 0.00005$ \\
Sardalya (5) & $0.00002 \pm 0.00001$ & $0.00002 \pm 0.00001$ & $0.00006 \pm 0.00003$ & $0.00007 \pm 0.00003$ \\
Somon (6) & $0.00005 \pm 0.00004$ & $0.00005 \pm 0.00005$ & $0.00004 \pm 0.00005$ & $0.00005 \pm 0.00005$ \\
Uskumru (8) & $0.00004 \pm 0.00006$ & $0.00005 \pm 0.00006$ & $0.00001 \pm 0.00001$ & $0.00001 \pm 0.00001$ \\
Levrek (1) & $0.00001 \pm 0.000003$ & $0.00001 \pm 0.000003$ & $0.000001 \pm 0.00005$ & $0.00008 \pm 0.00005$ \\
Toplam (66) & $0.00005 \pm 0.00008$ & $0.00006 \pm 0.00008$ & $0.00009 \pm 0.00006$ & $0.00001 \pm 0.000001$ \\
\hline
\end{tabular}

Tablo 3. Yetişkin bireylerin konserve balık tüketimlerine bağlı Al ve As maruziyet düzeyleri $\overline{\mathrm{X}} \pm \mathrm{SS}$

\begin{tabular}{lcccc}
\hline \multirow{2}{*}{$\begin{array}{l}\text { Balık Türü } \\
\text { (n) }\end{array}$} & \multicolumn{2}{c}{ Al (mg/kg VA/hafta) } & \multicolumn{2}{c}{ As (mg/kg VA/hafta) } \\
\cline { 2 - 5 } Ton (42) & Erkek & Kadın & Erkek & Kadın \\
Alabalık (2) & $0.00475 \pm 0.00321$ & $0.00514 \pm 0.00347$ & $0.00128 \pm 0.00072$ & $0.00139 \pm 0.00078$ \\
Hamsi (2) & $0.00745 \pm 0.00059$ & $0.00651 \pm 0.00203$ & $0.00067 \pm 0.00039$ & $0.00073 \pm 0.00043$ \\
Sardalya (5) & $0.00467 \pm 0.00277$ & $0.00808 \pm 0.00066$ & $0.00259 \pm 0.00009$ & $0.00281 \pm 0.00010$ \\
Somon (6) & $0.00499 \pm 0.00173$ & $0.00540 \pm 0.00296$ & $0.00843 \pm 0.00442$ & $0.00913 \pm 0.00478$ \\
Uskumru (8) & $0.00693 \pm 0.00528$ & $0.00747 \pm 0.00575$ & $0.00088 \pm 0.00066$ & $0.00096 \pm 0.00072$ \\
Levrek (1) & $0.00416 \pm 0.00045$ & $0.00444 \pm 0.00045$ & $0.00258 \pm 0.00058$ & $0.00280 \pm 0.00078$ \\
Toplam (66) & $0.00514 \pm 0.00340$ & $0.00556 \pm 0.00368$ & $0.00036 \pm 0.00001$ & $0.00039 \pm 0.00001$ \\
\hline
\end{tabular}




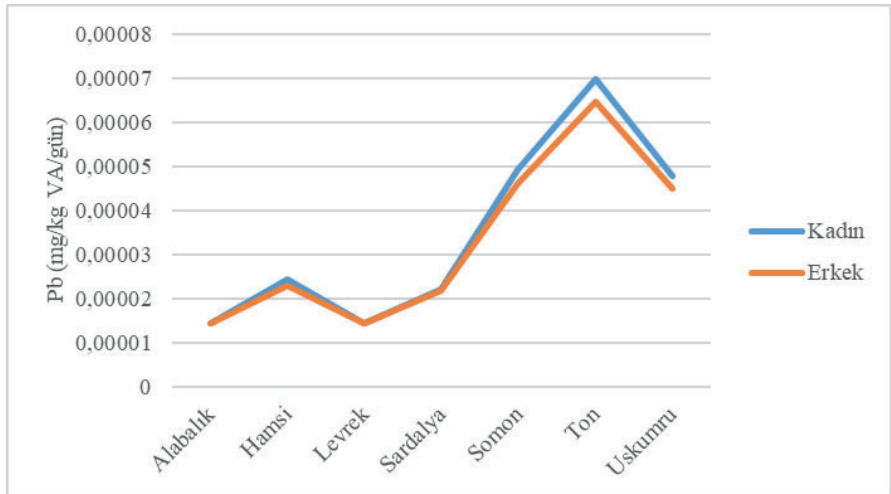

Şekil 1. Yetişkin bireylerin önerilen balık tüketimlerine göre $\mathrm{Pb}$ maruziyet düzeyleri (mg/kg VA/gün)

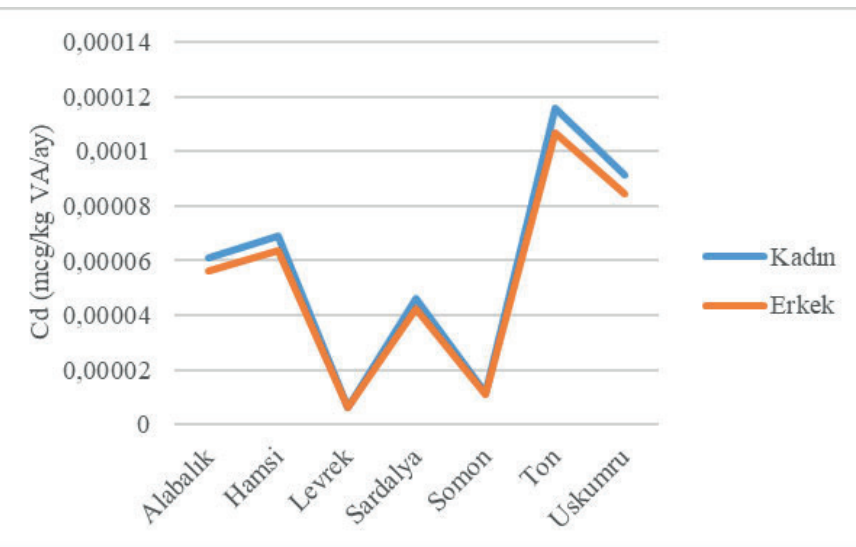

Şekil 2. Yetişkin bireylerin önerilen balık tüketimlerine göre Cd maruziyet düzeyleri (mcg/kg VA/ay)

\section{TARTIŞMA}

Literatürde besinlerdebulunan ağır metal miktarlarını saptamaya yönelik çalışmalar bulunmaktadır $(3,17,25)$. Balık ve deniz ürünleri ise ağır metal maruziyeti konusunda diğer besin gruplarına göre daha fazla dikkat çekmektedir. Ülkemizde konserve balık türlerinin (özellikle ton, sardalya, uskumru gibi balıklar) içerdikleri ağır metal konsantrasyonlarının saptanmasına yönelik çalışmalar bulunmaktadır (2629). Fakat konserve balık tüketimine bağlı olarak ağır metal maruziyet düzeyini inceleyen çalışma sayısı sinirlidir.

Besinlerde bulunan inorganik kurşun, Uluslararası Kanser Araştırma Ajansı'na (IARC- The International Agency for Research on Cancer) göre insanlar için olası karsinojenler grubunda (Grup 2A) yer alan toksik bir elementtir (30). Konserve balıklardaki

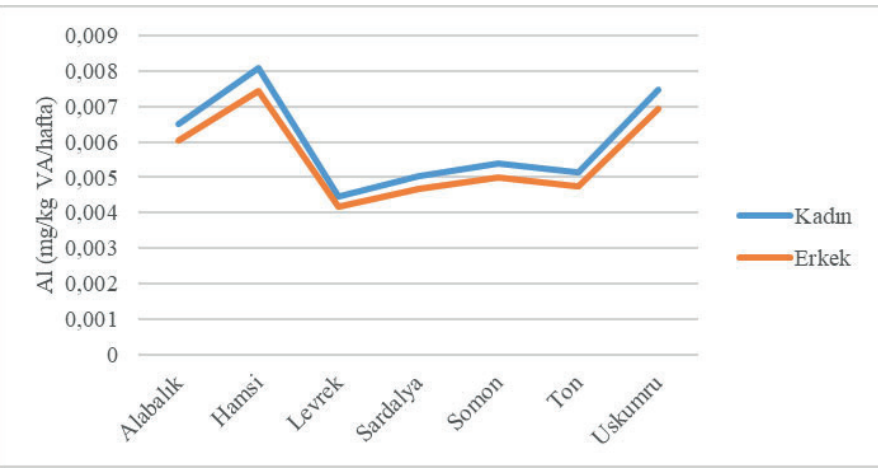

Şekil 3. Yetişkin bireylerin önerilen balık tüketimlerine göre $\mathrm{Al} \mathrm{maruziyet} \mathrm{düzeyleri} \mathrm{(mg/kg} \mathrm{VA/hafta)}$

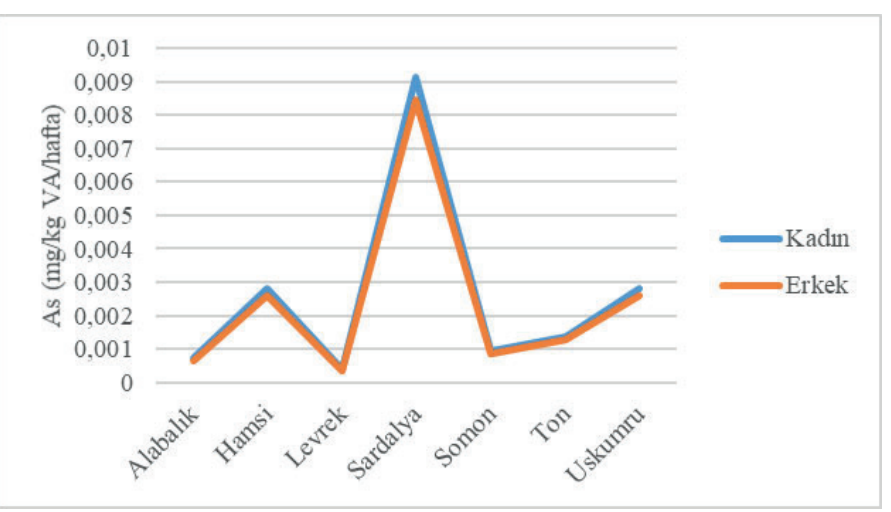

Şekil 4. Yetişkin bireylerin önerilen balık tüketimlerine göre As maruziyet düzeyleri (mg/kg VA/hafta)

$\mathrm{Pb}$ miktarını belirlemeye yönelik yapılan çalışma sonuçları geniş bir aralıkta değişmektedir (0.002-2.8 mg/kg) (3,17, 26-29,31-33). Ülkemizde Tüzen ve Soylak (2007)'ın çalışmasına göre konserve ton balığındaki $\mathrm{Pb}$ düzeyi $(0.10 \pm 0.01 \mathrm{mg} / \mathrm{kg})$ bu çalışmanın $(0.12 \pm 0.16$ $\mathrm{mg} / \mathrm{kg}$ ) sonuçlarına yakın bulunurken, hamsi, sardalya ve uskumru konservelerinin içeriği (sırasıyla $0.40 \pm 0.04 \mathrm{mg} / \mathrm{kg}, 0.09 \pm 0.01 \mathrm{mg} / \mathrm{kg}, 0.16 \pm 0.01 \mathrm{mg} / \mathrm{kg}$ ) bu çalışmadan (sırasıyla $0.04 \pm 0.01 \mathrm{mg} / \mathrm{kg}, 0.04 \pm 0.01$ $\mathrm{mg} / \mathrm{kg}, 0.08 \pm 0.10 \mathrm{mg} / \mathrm{kg}$ ) daha yüksek bulunmuştur (29). Benzer şekilde yapılan çalışmalarda, konserve balıkların $\mathrm{Pb}$ içeriği bu çalışmadan daha yüksek bulunmuştur (0.167-0.313 mg/kg arası) (26-28). Yapılan çalışmalarda konserve balıklar süzülerek analiz edilmiştir. $\mathrm{Bu}$ çalışmada ise konservenin içeriğindeki su ve yağ gibi diğer maddelerin ağır metal miktarları da önemli olduğundan süzülmeden 
homojenize edilerek analizler gerçekleştirilmiştir. Sonuçların birbirinden farklı olmasında bu faktörün etkili olabileceği düşünülmektedir.

Kadmiyum metali, Uluslararası Kanser Araştırma Enstitüsü’ne göre insanlar için karsinojen grubunda (Grup 1) bulunmaktadır (34). Çevre Koruma Ajansı (EPA)'na göre ise olası insan karsinojeni grubunda (Grup 1B) bulunmaktadır (9). Türkiye ve dünya genelinde yapılan çalışmalarda konserve balıklardaki Cd düzeyi birbirinden farklılık göstermektedir (2629,31,35). Ülkemizde 2007 ve 2011 yllarında yapllan bazı çalışmalarda, konserve ton, hamsi, alabalık, sardalya ve uskumru balıklarındaki Cd düzeyi bu çalışmanın sonuçlarından daha yüksek bulunmuştur (26-29). Balıkların ağır metal içeriğine bağlı olarak maruziyet düzeyi değişmektedir.

Balık ve su ürünleri tüketimi ile ağır metallere maruziyet düzeyine yönelik uluslararası çalışmalar da oldukça sınırlıdır (17,18,25,36). Polonya'da yapılan bir çalışmada ise yıllık konserve balık tüketimine göre (ylllı 1.5 kg) hesaplanan ağır metal maruziyet düzeyinin $(\mathrm{Pb}, \mathrm{Cd})$ maksimum tolere edilebilen düzeyin oldukça altında olduğu saptanmıştır (36). Benzer şekilde Rusya'da Anishchenko ve ark.'nın (17) yaptığı çalışmada, insan vücudunun günlük esansiyel yağ asidi ihtiyacının tamamının balık tüketimiyle karşılanması durumunda da $\mathrm{Pb}$ ve $\mathrm{Cd}$ maruziyetinin sağlık üzerinde risk oluşturacak düzeyde olmadığı belirtilmiştir. Yapılan önceki araştırmaların sonuçları $(17,36)$, bu çalışmanın sonuçlarıyla paralellik göstermektedir.

Ülkemizde konserve balıklardaki Al miktarının tayinine yönelik çalışmalar sinırlıdır. Tüzen ve Soylak'ın (29) çalışmasına göre konserve balıklarda Al düzeyleri 0.45-1.50 mg/kg aralığında bulunmuştur. Konserveler içerdikleri balık türlerine göre incelendiğinde bu çalışmanın sonuçları, Tüzen ve Soylak'ın (29) çalışmasından daha yüksek bulunmuştur. Buna göre günümüzde piyasada satışa sunulan konserve balıkların Al içeriğinin daha yüksek olduğu ve buna bağlı olarak Al maruziyet düzeyinin de daha yüksek olacağı düşünülmektedir. Bu konuda ülkemizde ve uluslararası alanda daha fazla çalışmaya ihtiyaç duyulmaktadır.

Arsenik, genellikle sularda saptanan bir ağır metaldir. Bu sebeple balık ve deniz ürünleri arsenik konusunda dikkat çeken bir besin grubudur. Besinlerde inorganik formda bulunan arsenik EPA tarafindan Grup A'da insan karsinojeni sınıfında belirtilmektedir (13). Ülkemizde konserve balıkların As içeriğine bağlı As maruziyetinin değerlendirildiği bir çalışmaya literatürde rastlanmamıştır. Gıda Katkı Maddeleri Ortak FAO/WHO Uzmanlar Komitesi (JECFA), 1988 yılında As için tolere edilebilir üst limiti $0.015 \mathrm{mg} / \mathrm{kg}$ VA/hafta olarak belirlemiştir. Fakat JECFA, 2011 yılında bu limitin koruyucu etkisinin olmadığını bildirerek güncel bir limit belirlememiştir. $\mathrm{Bu}$ durumda konserve balık tüketimiyle As maruziyetinin riskinin değerlendirilmesi güçtür. Literatürde konserve balıklarda As miktarının analizine yönelik çalışmalar bulunmaktadır. Konserve ton balıklarında As içeriğini inceleyen araştırmaların sonuçları, bu çalışmanın sonucundan daha yüksek bulunmuştur (31,32,37). İran'da yayınlanan bir sistematik derlemeye göre bireylerin ortalama konserve balık tüketimleri göz önünde bulundurulduğunda, yetişkin ve çocuklar için konserve ton balıklarının $\mathrm{Pb}, \mathrm{Cd}, \mathrm{Al}$ ve As yönünden karsinojenik risk taşımadığı saptanmıştır. Fakat konserve balıkların ağır metal içeriklerinin özellikle $\mathrm{Al}$ ve As yönünden izlenmesi gerektiği bildirilmiştir (38).

$\mathrm{Bu}$ araştırma sonuçlarına göre farklı içeriklere sahip konserve balıkların tüketimine bağlı olarak $\mathrm{Pb}, \mathrm{Cd}, \mathrm{Al}$ ve As maruziyet düzeyleri, farklı otoriteler tarafindan belirlenen limitlerin altında olmasına rağmen, toplumdaki risk grupları düşünüldüğünde belirlenen maruziyet düzeylerinin izlenmesine yönelik geniş çapta çalışmalar planlanmalı ve yürütülmelidir.

$\mathrm{Bu}$ araştırmanın bazı sinırlılıkları bulunmaktadır. Araştırmada toplumda farklı yaş grupları ve cinsiyete göre saptanan günlük konserve balık tüketimine bağlı risk değerlendirilmesinin yapılması planlanmış, ancak çalışma süresinin sınırlı olması nedeniyle bu saha uygulaması yapılamamıştır. Farklı yaş ve 
cinsiyete göre bireylerin taze ve/veya konserve olarak tükettikleri balık porsiyonlarının saptanarak risk değerlendirilmesinin yapılması çalışmayı güçlendirecek bir diğer faktördür. Ayrıca farklı mevsimlerde satın alınan taze balıkların ağır metal içeriğinin saptanmasının toplumdaki risk gruplarında balık tüketimi ile maruz kalınan ağır metallerin değerlendirilmesinde anahtar rol oynayacağ 1 düşünülmektedir.

\section{SONUÇ VE ÖNERILER}

Konserve balıklar ağır metal maruziyeti konusunda önemli bir kaynak olarak değerlendirilmektedir. Araştırmada Türkiye Beslenme Rehberi'nde (2015), yetişkin bireyler için önerilen haftalık 2 porsiyon balığın konserve şeklinde tüketilmesiyle farklı otoriteler tarafindan belirlenen maksimum $\mathrm{Pb}, \mathrm{Cd}, \mathrm{Al}$ ve As maruziyet limitlerini aşmadıkları saptanmıştır. Diyetimizde ağır metal maruziyetinin en az düzeyde olması için konserve balıklarda yasal düzenlemelere uygun olacak şekilde üretimden-tüketime kadar geçen her aşamada ağır metal kontaminasyonunu engelleyecek sürdürülebilir tedbirlerin alınması gereklidir.

Konserve balıkların içeriğindeki $\mathrm{Pb}, \mathrm{Cd}$, Al ve As düzeyi balık türüne bağlı olarak farklılık göstermektedir. Konserve balık türleri birbirinden farklı düzeyde besin değeri ve/veya kirliliğe sahip olduğu için tüm besin gruplarında olduğu gibi balık tüketimi konusunda da her yaş grubundaki bireyler tüketimde çeşitliliğe özen göstermelidir.

Ayrıca piyasada satışa sunulan farklı türde ve içeriğe sahip konserve balıkların günlük tüketim miktarlarına göre farklı yaş gruplarındaki bireylerin ağır metal maruziyetini değerlendiren çalışma sayısı da oldukça azdır. Bu konuda daha kapsamlı çalışmaların yapılması gerekmektedir.

Çıkar çatışması - Conflict of interest: Yazarlar çıkar çatışması olmadığını beyan ederler. - The authors declare that they have no conflict of interest.

\section{KAYNAKLAR}

1. Rehman K, Fatima F, Waheed I, Akash MSH. Prevalence of exposure of heavy metals and their impact on health consequences. J Cell Biochem. 2018;119(1):157-84.

2. Joint FAO/WHO Food Standards Programme (Codex Alimentarius) Commission: Procedural Manual 21st Edition, Rome: World Health Organization, Food and Agriculture Organization of the United Nations; 2013. $214 \mathrm{p}$.

3. Hosseini SV, Sobhanardakani S, Miandare HK, Harsij $\mathrm{M}$, Regenstein JM. Determination of toxic $(\mathrm{Pb}, \mathrm{Cd})$ and essential (Zn, Mn) metals in canned tuna fish produced in Iran. J Environ Health Sci Eng. 2015;13:59.

4. Flora G, Gupta D, Tiwari A. Toxicity of lead: a review with recent updates. Interdiscip Toxicol. 2012;5(2):4758.

5. Obeng-Gyasi E. Sources of lead exposure in various countries. Rev Environ Health. 2019;34(1):25-34.

6. Agency for Toxic Substances \& Disease Registry (ATSDR). Toxicological profile for lead. United States Department of Health and Human Services. 2007;1:582.

7. Soylemez E, Kayaalti Z. Toxic effect of lead exposure to newborn and children. The Turkish Journal of Occupational/Environmental Medicine and Safety. 2017;2(1):296-296.

8. Jaishankar M, Tseten T, Anbalagan N, Mathew BB, Beeregowda KN. Toxicity, mechanism and health effects of some heavy metals. Interdiscip toxicol. 2014;7(2):6072.

9. Faroon O, Ashizawa A, Wright S, Tucker P, Jenkins K, Ingerman L, et al. Toxicological profile for Cadmium. Atlanta (GA): Agency for Toxic Substances and Disease Registry (ATSDR); 2012.p 1-487.

10. Ertl K, Goessler W. Aluminium in foodstuff and the influence of aluminium foil used for food preparation or short time storage. Food Addit Contam Part B. 2018;11(2):153-9.

11. Ma N, Liu ZP, Yang DJ, Liang J, Zhu, JH, Xu HB, et al. Risk assessment of dietary exposure to aluminium in the Chinese population. Food Addit Contam Part A. 2016;33(10):1557-62.

12. U.S. Department of Health and Human Services Public Health Service Agency for Toxic Substances \& Disease Registry (ATSDR). Toxicological profile for arsenic, ATSDR; 2007. p 1-20.

13. International Agency for Research on Cancer (IARC). Arsenic, metals, fibres and dusts volume 100C. IARC Monogr Eval Carcinog Risks Hum. 2012. Available at: https://monographs.iarc.fr/wp-content/uploads/2018/06/ mono100C.pdf Accessed: February 8, 2020. 
14. Uneyama C, Toda M, Yamamoto M, Morikawa K. Arsenic in various foods: cumulative data. Food Addit Contam. 2007;24(5):447-534.

15. Kakkar P, Jaffery FN. Biological markers for metal toxicity. Environ Toxicol Pharmacol. 2005;19(2):335-49.

16. Türkiye Beslenme ve Sağlık Araştırması 2010 Beslenme Durumu ve Alışkanlıklarının Değerlendirilmesi Sonuç Raporu. Sağlık Araştırmaları Genel Müdürlüğü, Sağlık Bakanlığı. Erişim: https://hsgm.saglik.gov.tr/depo/ birimler/saglikli-beslenme-hareketli-hayat-db/Yayinlar/ kitaplar/diger-kitaplar/TBSA-Beslenme-Yayini.pdf Erişim Tarihi: 16 Temmuz 2020.

17. Anishchenko OV, Sushchik NN, Makhutova ON, Kalachova GS, Gribovskaya IV, Morgun VN, et al. Benefit-risk ratio of canned pacific saury (Cololabis saira) intake: Essential fatty acids vs. heavy metals. Food Chem Toxicol. 2017;101(Supplement C):8-14

18. Yi Y, Tang C, Yi T, Yang Z, Zhang S. Health risk assessment of heavy metals in fish and accumulation patterns in food web in the upper Yangtze River, China. Ecotoxicol Environ Saf. 2017;145(Supplement C):295-302.

19. Joint FAO/WHO Expert Committee on Food Additives (JECFA). Meeting \& World Health Organization. Evaluation of Certain Food Additives: Seventy-seventh Report of the Joint FAO/WHO Expert Committee on Food Additives, Italy: World Health Organization; 2013. p.86. Technical Report Series 983.

20. Joint FAO/WHO Expert Committee on Food Additives (JECFA). Meeting \& World Health Organization. Evaluation of Certain Food Additives: Seventy-fourth Report of the Joint FAO/WHO Expert Committee on Food Additives, Italy: World Health Organization; 2011. p.148. Technical Report Series 966.

21. Food and Drug Administration. Lead in Food, Foodwares and Dietary Supplements. 2019. Available at: https:// www.fda.gov/food/metals/lead-food-foodwares-anddietary-supplements Accessed February 8, 2020.

22. Joint FAO/WHO Expert Committee on Food Additives (JECFA). Meeting \& World Health Organization. Evaluation of Certain Contaminants in Food: Seventysecond report of the JECFA, Italy: World Health Organization; 2010. p.115. Technical Report Series 959.

23. T.C. Sağlık Bakanlığı,Türkiye Beslenme Rehberi (TÜBER). 2015. T.C. Sağlık Bakanlığı Yayın No: 1031, Ankara 2016.

24. Hayran M, Hayran M. Sağlık Araştırmaları İçin Temel İstatistik. 1. Baskı. Ankara: Omega Araştırma; 2011. 49$84 \mathrm{~s}$.

25. Pastorelli A, Baldini M, Stacchini P, Baldini G, Morelli S, Sagratella E, et al. Human exposure to lead, cadmium and mercury through fish and seafood product consumption in Italy: a pilot evaluation. Food Addit Contam: Part A. 2012;29(12):1913-21.
26. Mol S. Levels of selected trace metals in canned tuna fish produced in Turkey. Journal of Food Composit Anal. 2011;24(1):66-9.

27. Mol S. Determination of trace metals in canned anchovies and canned rainbow trouts. Food Chem Toxicol. 2011;49(2):348-51.

28. Mol S. Levels of heavy metals in canned bonito, sardines, and mackerel produced in Turkey. Biol Trace Elem Res. 2011;143(2):974-82.

29. Tuzen M, Soylak M. Determination of trace metals in canned fish marketed in Turkey. Food Chem. 2007;101(4):1378-82.

30. International Agency for Research on Cancer (IARC). List of Classifications Agents classified by the IARC Monographs, Volumes 1-124. 2006. Available at: https:// monographs.iarc.fr/list-of-classifications Accessed February 8, 2020.

31. Popovic AR, Djinovic-Stojanovic JM, Djordjevic DS, Relic DJ, Vranic DV, Milijasevic MP, et al. Levels of toxic elements in canned fish from the Serbian markets and their health risks assessment. J Food Compost Anal. 2018;67:70-6.

32. Massadeh AM, Allah A, Al-Massaedh T, Kharibeh S. Determination of selected elements in canned food sold in Jordan markets. Environ Sci Pollut Res. 2018;25(4):3501-9.

33. Iwegbue CM. Metal concentrations in selected brands of canned fish in Nigeria: estimation of dietary intakes and target hazard quotients. Environ Monit Assess. 2015;187(3):85.

34. International Agency for Research on Cancer. Cadmium and cadmium compounds. IARC Monographs-100C. 2018. Available at: https://monographs.iarc.fr/wpcontent/uploads/2018/06/mono100C-8.pdf Accessed February 8, 2020.

35. Novakov NJ, Mihaljev ZA, Kartalovic BD, Blagojevic BJ, Petrovic JM, Cirkovic MA, et al. Heavy metals and PAHs in canned fish supplies on the Serbian market. Food Addit Contam Part B Surveill. 2017;10(3):208-15.

36. Usydus Z, Szlinder-Richert J, Polak-Juszczak L, Kanderska J, Adamczyk M, Malesa-Ciecwierz M, et al. Food of marine origin: between benefits and potential risks. Part I. Canned fish on the Polish market. Food Chem. 2008;111(3):556-63.

37. Kaňa A, Koplík R, Braeuer S, Goessler W, Mestek O. Analysis of main arsenic species in canned fish marketed in the Czech Republic and Austria. J Food Chem Nanotechol. 2018;4(1):10-7.

38. Rahmani J, Fakhri Y, Shahsavani A, Bahmani Z, Urbina MA, Chirumbolo S, et al. A systematic review and metaanalysis of metal concentrations in canned tuna fish in Iran and human health risk assessment. Food Chem Toxicol. 2018;118:753-65. 